\title{
Predictors of Anxiety-Induced Sleep Disturbance among in-School Adolescents in Ghana: Evidence from the 2012 Global School-Based Health Survey
}

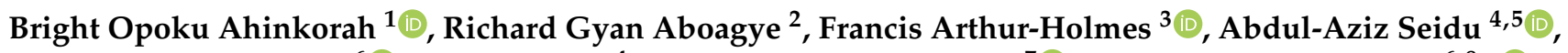 \\ James Boadu Frimpong ${ }^{6}{ }^{(0}$, Eugene Budu ${ }^{4}$, Bernard Mensah Amoako ${ }^{7}{ }^{(1)}$ and John Elvis Hagan, Jr. ${ }^{6,8, *(D)}$ \\ 1 Faculty of Health, School of Public Health, University of Technology Sydney, Sydney, NSW 2007, Australia; \\ brightahinkorah@gmail.com \\ 2 School of Public Health, University of Health and Allied Sciences, Ho PMB 31, Ghana; \\ raboagye18@sph.uhas.edu.gh \\ 3 Department of Sociology and Social Policy, Lingnan University, 8 Castle Peak Road, Tuen Mun, Hong Kong; \\ frarthur88@gmail.com \\ 4 Department of Population and Health, University of Cape Coast, Cape Coast PMB TF0494, Ghana; \\ abdul-aziz.seidu@stu.ucc.edu.gh (A.-A.S.); budueugene@gmail.com (E.B.) \\ 5 College of Public Health, Medical and Veterinary Services, James Cook University, \\ Townsville, QLD 4811, Australia \\ 6 Department of Health, Physical Education, and Recreation, University of Cape Coast, \\ Cape Coast PMB TF0494, Ghana; frimpongboadujames@gmail.com \\ 7 Department of Counselling Psychology, University of Education, Winneba, Winneba PMB 25, Ghana; \\ bmamoako@uew.edu.gh \\ check for \\ updates \\ 8 Neurocognition and Action-Biomechanics-Research Group, Faculty of Psychology and Sport Sciences, \\ Bielefeld University, Postfach 1001 31, 33501 Bielefeld, Germany \\ * Correspondence: elvis.hagan@ucc.edu.gh
}

Citation: Ahinkorah, B.O.; Aboagye, R.G.; Arthur-Holmes, F.; Seidu, A.-A.; Frimpong, J.B.; Budu, E.; Amoako, B.M.; Hagan, J.E., Jr. Predictors of Anxiety-Induced Sleep Disturbance among in-School Adolescents in Ghana: Evidence from the 2012 Global School-Based Health Survey. Behav. Sci. 2021, 11, 20 https://doi.org/10.3390/bs11020020

Received: 21 December 2020

Accepted: 22 January 2021

Published: 1 February 2021

Publisher's Note: MDPI stays neutral with regard to jurisdictional claims in published maps and institutional affiliations.

Copyright: (c) 2021 by the authors. Licensee MDPI, Basel, Switzerland. This article is an open access article distributed under the terms and conditions of the Creative Commons Attribution (CC BY) license (https:// creativecommons.org/licenses/by/ $4.0 /)$.

\begin{abstract}
Background: Psychological problems of adolescents have become a global health and safety concern. Empirical evidence has shown that adolescents experience diverse mental health conditions (e.g., anxiety, depression, and emotional disorders). However, research on anxiety-induced sleep disturbance among in-school adolescents has received less attention, particularly in lowand middle-income countries. This study's central focus was to examine factors associated with $\mathrm{t}$ anxiety-induced sleep disturbance among in-school adolescents in Ghana. (2) Methods: Analysis was performed using the 2012 Global School-based Health Survey (GSHS). A sample of 1342 in-school adolescents was included in the analysis. The outcome variable was anxiety-induced sleep disturbance reported during the past 12 months. Frequencies, percentages, chi-square, and multivariable logistic regression analyses were conducted. Results from the multivariable logistic regression analysis were presented as crude and adjusted odds ratios at 95\% confidence intervals (CIs) and with a statistical significance declared at $p<0.05$. (3) Results: Adolescents who went hungry were more likely to report anxiety-induced sleep disturbance compared to their counterparts who did not report hunger $(\mathrm{aOR}=1.68, \mathrm{CI}=1.10,2.57)$. The odds of anxiety-induced sleep disturbance were higher among adolescents who felt lonely compared to those that never felt lonely $(\mathrm{aOR}=2.82, \mathrm{CI}=1.98,4.01$ ). Adolescents who had sustained injury were more likely to have anxiety-induced sleep disturbance $(\mathrm{aOR}=1.49, \mathrm{CI}=1.03,2.14)$ compared to those who had no injury. Compared to adolescents who never had suicidal ideations, those who reported experiencing suicidal ideations had higher odds of anxiety-induced sleep disturbance $(\mathrm{aOR}=1.68, \mathrm{CI}=1.05,2.71)$. (4) Conclusions: Anxiety-induced sleep disturbance among in-school adolescents were significantly influenced by the psychosocial determinants such as hunger, loneliness, injury, and suicidal ideation in this study. The findings can help design appropriate interventions through effective strategies (e.g., early school-based screening, cognitive-behavioral therapy, face-face counseling services) to reduce psychosocial problems among in-school adolescents in Ghana.
\end{abstract}

Keywords: Ghana; in-school adolescents; hunger; loneliness; cognitive-behavioral; suicidal ideations; therapy 


\section{Introduction}

Psychological problems of adolescents have become a global and safety concern [1]. Costello et al. [2] asserted that symptoms of anxiety are among the health problems affecting adolescents. According to the World Health Organization [3], "mental health conditions account for $16 \%$ of the global burden of disease and injury in people aged 10-19 years". About $10-20 \%$ of adolescents worldwide experience mental health conditions [4]. However, these health conditions are often undetected and untreated [4-6]. As is argued, most in-school adolescents experience mental health conditions through psychological distress from sexual and social relations decisions and assignment/examination worries [7-9].

Globally, "anxiety is the ninth leading cause of illness and disability for adolescents aged 15-19 and sixth for those aged 10-14" [3]. In sub-Saharan Africa (SSA), depression and anxiety are the most common mental disorders [10,11]. A wide range of symptoms of anxiety-induced sleep disturbance in adolescents include sleeplessness, restlessness, intermittent nighttime awakenings, and fatigue as a result of different forms of anxiety disorders: generalized anxiety disorder, separation anxiety disorder, panic disorder, social phobia, specific phobia, obsessive-compulsive disorder, and posttraumatic or acute stress disorder [12,13]. Anxiety-induced sleep disturbance refers to poor sleep quality, clinical insomnia, and/or alterations or deficits in sleep as a result of loneliness (either social or emotional), worry, sleep disturbance, and excessive fear [13-16]. Parekh [13] argues that anxiety can signal us of any danger and then helps us to deal with it. However, some adolescents who experience symptoms of anxiety resort to unacceptable behavior (such as suicide, fights, and stealing), tobacco use and consumption of illicit drugs [14,17].

Empirical evidence has shown that adolescents' mental health conditions include depression, anxiety, emotional disorders, post-traumatic stress, and psychosocial distress $[1,7,18-20]$. However, research on anxiety-induced sleep disturbance among in-school adolescents has received less attention, particularly in low- and middle-income countries. Thus, there is little understanding of the determinants of anxiety-induced sleep disturbance in these countries, particularly in sub-Saharan African countries. Few studies on anxietyinduced sleep disturbance among in-school adolescents have shown the prevalence and its correlates [1,16,21-23]. For instance, Khan and Khan [1] reported 4.7\% of anxiety among adolescents in Bangladesh. Khan and associates further observed that anxiety significantly increases the likelihood of adolescents' suicidal ideation, plans, and attempts as well as alcohol and drug abuse. A study conducted by Abbo et al., [21] in Uganda found 26.6\% prevalence of anxiety among children aged 3-19 years. A similar study [22] has found a varied prevalence rate of anxiety among adolescents aged 13-18 years.

Up until now, several factors (e.g., socio-demographic- age, school, or grade level; environmental stressors or psychosocial factors- alcohol/drug use, examination workload, loneliness, low self-esteem, victimization) have been found to be associated with anxietyinduced sleep disturbance among in-school adolescents [1,14,16,23-26]. However, these factors may vary in different populations. For example, in a study among in-school adolescents in Ghana, loneliness was reported among $18.4 \%$ of school-going adolescents in the 2012 Global School-based Health Survey [16]. Although the study found that anxiety was strongly associated with loneliness, it was used as an independent variable to check its prediction on loneliness. However, loneliness as a determinant of anxietyinduced sleep disturbance among in-school adolescents was not established. Thus, the predictors of anxiety-induced sleep disturbance of in-school adolescents in Ghana remain uncharted. This study, therefore, seeks to utilize data from the 2012 Global School-based Health Survey (GSHS) of Ghana to determine the factors that predict anxiety-induced sleep disturbance among in-school adolescents to fill this research gap. Findings of the study could provide useful information for researchers and policy direction related to the diagnosis and management of anxiety symptoms among adolescents in Ghana. 


\section{Materials and Methods}

\subsection{Study Design}

This cross-sectional study used a secondary data from the 2012 GSHS. We relied on the "Strengthening the Reporting of Observational Studies in Epidemiology" (STROBE) statement in writing the manuscript. The GSHS is a nationwide study conducted among in-school adolescents to determine the risk and protective factors of health and behavioral problems [27]. The GSHS study was carried out in Ghana with support and assistance from the World Health Organization (WHO), the Centre for Disease Control and Prevention (CDC), and the Ministry of Education (MoE). A close-ended questionnaire was used to obtain the primary data. A two-staged probability sampling technique was used to recruit students from 25 senior high schools (SHS) across the then 10 regions in Ghana. First, study schools were proportionally selected based on the school's population (enrolment size) using a systematic random sampling method. The second stage involved the random selection of study classes from each selected school. These sampling techniques used provide the avenue to generalize the results to in-school adolescents in a broader context. Moreover, the design and techniques employed offer the opportunity to subject the data to rigorous statistical analysis. A total of 1984 students from SHSs participated in the study. The overall, school and students' response rates were $71 \%, 96 \%$, and $74 \%$, respectively. However, 1342 in-school adolescents with complete cases on all the variables of interest were included in the study. The dataset is available freely at https:/ / www.who.int/ncds / surveillance/gshs/ghanadataset/en/.

\subsection{Study Variables}

\subsubsection{Outcome Variable}

The main outcome variable in the study was anxiety-induced sleep disturbance. This variable was derived from the question, "During the past 12 months, how often have you been so worried about something that you could not sleep at night?" The responses were $1=$ never, $2=$ rarely, $3=$ sometimes, $4=$ most of the times, and $5=$ always. The responses were dichotomized into "no anxiety (0)" and "anxiety (1)". If the student responded never/rarely/sometimes, the study respondent was then categorized as "not felt anxious" while those who responded as "most at times" or "always" were grouped as "felt anxious" [1].

\subsubsection{Explanatory Variables}

A total of twenty-two explanatory variables were used in the present study. The variables were selected from a review of the literature [1] and their availability in the dataset. The variables included age, sex, grade, hunger, physical fighting, physical attack, injury, truancy, alcohol use, cigarette smoking, marijuana use, tobacco use, peer support, close friends, suicidal ideation, suicidal attempt, loneliness, bullied, parental or guardian supervision, parental or guardian bonding, parental or guardian connectedness, and parental or guardian respect for privacy. All the variables were recoded into a binary form, except grade. The detailed description of the variables and the recoded responses are in the supplementary file attached (Table S1).

\subsection{Statistical Analyses}

Data for this study was extracted, cleaned, recoded, and analyzed using Stata software version 16.0 (Stata Corporation, College Station, TX, USA). Variables with complete cases were included in the final analysis. Both descriptive and inferential analyses were performed. Descriptively, frequencies, and percentages were used to present the results. The inferential analysis was subdivided into two stages. The first stage consisted of a Chi-square test, conducted to examine the relationship between anxiety-induced sleep disturbance and explanatory variables. The statistically significant variables (i.e., showed a $p<0.05$ ) were subsequently included in a multivariable analysis. At the second stage, multivariable binary logistic regression analysis was also carried out. The binary logistic 
regression model was used because the main outcome variable in the data was recoded to dichotomous which met the basic assumption for the use of binary logistic regression. Two regression models were used during the binary logistic regression analysis. The first model (Model I) was used to determine the strength of the association between each of the explanatory variables and anxiety-induced sleep disturbance. The second model (Model II) was built to examine the strength of the association between all the significant explanatory variables from the Chi-square analysis and anxiety-induced sleep disturbance. The results in the binary logistic regression analyses for Model I and Model II were presented using the crude odds ratios (cOR) and adjusted odds ratios (aOR) with their corresponding 95\% confidence intervals (CIs). Statistical significance was set at $p<0.05$. During the analysis, we adjusted for the complex design employed in the data collection. Multicollinearity was checked using the Variance Inflation Factor (VIF). A mean VIF of 1.24 shows no evidence of multicollinearity in the data.

\subsection{Ethical Consideration}

Ethical requirements for the use of both minors and adults were adhered to during the survey. First, institutional permission for the conduct of the study was sought from the MoE and Heads of selected schools. All the ethical guidelines and procedures regarding the conduct of research among students were strictly adhered to during the study. Prior to the data collection, written permission was sought from the Ghana Education Service (GES), heads, and teachers of the selected schools. Written informed consent was obtained from students aged 18 years and above. Child agreement was sought from students below 18 years. Additionally, a written parental or guardian consent was obtained from those whose wards were minors before their inclusion in the study.

\section{Results}

\subsection{Socio-Demographic Characteristics of the Respondents}

Of the 1342 in-school adolescents who were included in the study, $97.2 \%$ were aged 15 years or older. More than half (55.2\%) were males and the rest being females (44.8\%). The majority (32.0\%) of the adolescents were in SHS3, followed by SHS1 (29.5\%), and lowest in SHS2 (18.8\%). Only a few (12.1\%) went hungry in the past 30 days before the study.

\subsection{Bivariate Analysis of the Proportion of Anxiety-Induced Sleep Disturbance among Adolescents in Ghana}

Table 1 shows the prevalence of anxiety-induced sleep disturbance and its distribution among the in-school adolescents in Ghana. The results showed that the prevalence of anxiety-induced sleep disturbance among the adolescents was $13.9 \%$. In the Chi-square analysis, hunger $\left(\chi^{2}=15.7, p<0.001\right)$, loneliness $\left(\chi^{2}=53.1, p<0.001\right)$, suicidal ideation $\left(\chi^{2}=19.4, p<0.001\right)$, suicidal attempt $\left(\chi^{2}=10.0, p<0.001\right)$, bullied $\left(\chi^{2}=9.5, p=0.002\right)$, injured $\left(\chi^{2}=17.2, p<0.001\right)$, engaged in fight $\left(\chi^{2}=4.3, p=0.038\right)$, attacked $\left(\chi^{2}=11.7\right.$, $p=0.001)$, and parental or guardian respect for privacy $\left(\chi^{2}=7.5, p=0.006\right)$ were significantly associated with anxiety-induced sleep disturbance among the in-school adolescents.

\subsection{Multivariable Regression Analysis on Predictors of Anxiety-Induced Sleep Disturbance among In-School Adolescents in Ghana}

Table 2 presents the multivariable logistic regression results of the association between anxiety-induced sleep disturbance and the explanatory variables. The results from the crude odds ratio (Model I) showed that all the explanatory variables included from the bivariate analysis showed significant associations with anxiety-induced sleep disturbance. However, in the adjusted model (Model II), only ever went hungry, loneliness, injury, and suicidal ideation showed statistically significant associations with anxiety-induced sleep disturbance. Adolescents who went hungry were more likely to report anxiety-induced sleep disturbance compared to their counterparts who did not report hunger $(\mathrm{aOR}=1.68$, $\mathrm{CI}=1.10,2.57)$. The odds of anxiety-induced sleep disturbance were high among adolescents who felt lonely compared to those who never felt lonely $(\mathrm{aOR}=2.82, \mathrm{CI}=1.98$, 
4.01). Adolescents who had sustained injury were more likely to have anxiety-induced sleep disturbance $(\mathrm{aOR}=1.49, \mathrm{CI}=1.03,2.14)$ compared to those who had no injury. Compared to adolescents who never had suicidal ideations, those who reported experiencing suicidal ideations had higher odds of anxiety-induced sleep disturbance ( $\mathrm{AOR}=1.68$, $\mathrm{CI}=1.05,2.71)$.

Table 1. Bivariate Analysis of the Proportion of Anxiety-induced sleep disturbance among In-school Adolescents in Ghana.

\begin{tabular}{|c|c|c|c|c|c|}
\hline \multirow[t]{2}{*}{ Variable } & \multicolumn{2}{|c|}{$\mathbf{N}=1342$} & \multicolumn{2}{|c|}{$\begin{array}{l}\text { Anxiety-Induced } \\
\text { Sleep Disturbance }\end{array}$} & \multirow[t]{2}{*}{$\begin{array}{l}\text { Chi-Square } \\
\chi^{2}(p \text {-Value })\end{array}$} \\
\hline & Frequency & Percent & No & Yes & \\
\hline $\begin{array}{l}\text { Anxiety-induced sleep } \\
\text { disturbance }\end{array}$ & & & 86.1 & 13.9 & \\
\hline Age & & & & & $0.02(0.899)$ \\
\hline $12-14$ years & 38 & 2.8 & 86.8 & 13.2 & \\
\hline $15-18$ years & 1304 & 97.2 & 86.1 & 13.9 & \\
\hline Sex & & & & & $0.8(0.365)$ \\
\hline Female & 601 & 44.8 & 85.2 & 14.8 & \\
\hline Male & 741 & 55.2 & 86.9 & 13.1 & \\
\hline Grade & & & & & $0.7(0.865)$ \\
\hline SHS 1 & 396 & 29.5 & 86.1 & 13.9 & \\
\hline SHS 2 & 253 & 18.8 & 85.0 & 15.0 & \\
\hline SHS 3 & 429 & 32.0 & 87.2 & 12.8 & \\
\hline SHS 4 & 264 & 19.7 & 85.6 & 14.4 & \\
\hline Ever went hungry & & & & & $15.7(<0.001)$ \\
\hline No & 1179 & 87.9 & 87.5 & 12.5 & \\
\hline Yes & 163 & 12.1 & 76.1 & 23.9 & \\
\hline Loneliness & & & & & $53.1(<0.001)$ \\
\hline No & 1100 & 82.0 & 89.4 & 10.6 & \\
\hline Yes & 242 & 18.0 & 71.5 & 28.5 & \\
\hline Truant & & & & & $0.5(0.459)$ \\
\hline No & 933 & 69.5 & 86.6 & 13.4 & \\
\hline Yes & 409 & 30.5 & 85.1 & 14.9 & \\
\hline Suicidal ideation & & & & & $19.4(<0.001)$ \\
\hline No & 1134 & 84.5 & 87.9 & 12.1 & \\
\hline Yes & 208 & 15.5 & 76.4 & 23.6 & \\
\hline Suicidal attempt & & & & & $10.0(0.002)$ \\
\hline No & 1081 & 80.6 & 87.6 & 12.4 & \\
\hline Yes & 261 & 19.4 & 80.1 & 19.9 & \\
\hline Alcohol use & & & & & $1.2(0.264)$ \\
\hline No & 1187 & 88.5 & 86.5 & 13.5 & \\
\hline Yes & 155 & 11.5 & 83.2 & 16.8 & \\
\hline Tobacco use & & & & & $0.7(0.397)$ \\
\hline No & 1279 & 95.3 & 86.3 & 13.7 & \\
\hline Yes & 63 & 4.7 & 82.5 & 17.5 & \\
\hline Smoking & & & & & $0.1(0.780)$ \\
\hline No & 1303 & 97.1 & 86.2 & 13.8 & \\
\hline Yes & 39 & 2.9 & 84.6 & 15.4 & \\
\hline Marijuana use & & & & & $0.1(0.822)$ \\
\hline No & 1310 & 97.6 & 86.1 & 13.9 & \\
\hline Yes & 32 & 2.4 & 87.5 & 12.5 & \\
\hline Bullied & & & & & $9.5(0.002)$ \\
\hline No & 788 & 58.7 & 88.6 & 11.4 & \\
\hline Yes & 554 & 41.3 & 82.7 & 17.3 & \\
\hline Injury & & & & & $17.2(<0.001)$ \\
\hline No & 651 & 48.5 & 90.2 & 9.8 & \\
\hline Yes & 691 & 51.5 & 82.3 & 17.7 & \\
\hline
\end{tabular}


Table 1. Cont.

\begin{tabular}{|c|c|c|c|c|c|}
\hline \multirow[t]{2}{*}{ Variable } & \multicolumn{2}{|c|}{$N=1342$} & \multicolumn{2}{|c|}{$\begin{array}{l}\text { Anxiety-Induced } \\
\text { Sleep Disturbance }\end{array}$} & \multirow{2}{*}{$\begin{array}{l}\text { Chi-Square } \\
\chi^{2}(p \text {-Value })\end{array}$} \\
\hline & Frequency & Percent & No & Yes & \\
\hline \multicolumn{5}{|l|}{ Engaged in fight } & $4.3(0.038)$ \\
\hline No & 972 & 72.4 & 87.3 & 12.7 & \\
\hline Yes & 370 & 27.6 & 83.0 & 17.0 & \\
\hline \multicolumn{5}{|l|}{ Attacked } & $11.7(0.001)$ \\
\hline No & 857 & 63.9 & 88.6 & 11.4 & \\
\hline Yes & 485 & 36.1 & 81.9 & 18.1 & \\
\hline \multicolumn{5}{|l|}{ Number of close friends } & $0.1(0.782)$ \\
\hline No & 179 & 13.3 & 85.5 & 14.5 & \\
\hline Yes & 1163 & 86.7 & 86.2 & 13.8 & \\
\hline \multicolumn{5}{|l|}{ Peer support } & $0.5(0.465)$ \\
\hline No & 870 & 64.8 & 85.6 & 14.4 & \\
\hline Yes & 472 & 35.2 & 87.1 & 12.9 & \\
\hline \multicolumn{5}{|c|}{ Parental or guardian supervision } & $0.2(0.683)$ \\
\hline No & 776 & 57.8 & 86.5 & 13.5 & \\
\hline Yes & 566 & 42.2 & 85.7 & 14.3 & \\
\hline \multicolumn{5}{|c|}{ Parental or guardian connectedness } & $0.6(0.457)$ \\
\hline No & 731 & 54.5 & 85.5 & 14.5 & \\
\hline Yes & 611 & 45.5 & 86.9 & 13.1 & \\
\hline \multicolumn{5}{|l|}{$\begin{array}{l}\text { Parental or guardian } \\
\text { bonding }\end{array}$} & $0.02(0.892)$ \\
\hline No & 802 & 59.8 & 86.0 & 14.0 & \\
\hline Yes & 540 & 40.2 & 86.3 & 13.7 & \\
\hline \multicolumn{5}{|c|}{ Parental or guardian respect for privacy } & $7.5(0.006)$ \\
\hline No & 1130 & 84.2 & 87.3 & 12.7 & \\
\hline Yes & 212 & 15.8 & 80.2 & 13.7 & \\
\hline
\end{tabular}

Table 2. Multivariable Analysis on Predictors of Anxiety-induced sleep disturbance among In-school Adolescents in Ghana.

\begin{tabular}{|c|c|c|}
\hline \multirow[t]{2}{*}{ Variable } & \multicolumn{2}{|c|}{ Anxiety-Induced Sleep Disturbance } \\
\hline & $\begin{array}{c}\text { Model I } \\
\text { COR }(95 \% \text { CI) } p \text {-Value }\end{array}$ & $\begin{array}{c}\text { Model II } \\
\text { AOR }(95 \% \text { CI) } p \text {-Value }\end{array}$ \\
\hline \multicolumn{3}{|c|}{ Ever went hungry } \\
\hline No & Ref & Ref \\
\hline Yes & $2.21(1.48,3.29)<0.001$ & $1.68(1.10,2.57) 0.016$ \\
\hline \multicolumn{3}{|l|}{ Loneliness } \\
\hline No & Ref & Ref \\
\hline Yes & $3.35(2.39,4.70)<0.001$ & $2.82(1.98,4.01)<0.001$ \\
\hline \multicolumn{3}{|l|}{ Bullied } \\
\hline No & Ref & Ref \\
\hline Yes & $1.63(1.19,2.22) 0.002$ & $1.09(0.77,1.55) 0.621$ \\
\hline \multicolumn{3}{|l|}{ Injury } \\
\hline No & Ref & Ref \\
\hline Yes & $1.97(1.42,2.72)<0.001$ & $1.49(1.03,2.14) 0.032$ \\
\hline \multicolumn{3}{|c|}{ Engaged in fight } \\
\hline No & Ref & Ref \\
\hline Yes & $1.42(1.02,1.97) 0.039$ & $0.98(0.67,1.43) 0.911$ \\
\hline \multicolumn{3}{|l|}{ Attacked } \\
\hline No & Ref & Ref \\
\hline Yes & $1.72(1.26,2.35) 0.001$ & $1.38(0.97,1.96) 0.077$ \\
\hline \multicolumn{3}{|c|}{ Suicidal ideation } \\
\hline No & Ref & Ref \\
\hline Yes & $2.24(1.55,3.24)<0.001$ & $1.68(1.05,2.71) 0.031$ \\
\hline
\end{tabular}


Table 2. Cont.

\begin{tabular}{|c|c|c|}
\hline Variable & \multicolumn{2}{|c|}{ Anxiety-Induced Sleep Disturbance } \\
\hline \multicolumn{3}{|c|}{ Suicidal attempt } \\
\hline No & Ref & Ref \\
\hline Yes & $1.76(1.23,2.50) 0.002$ & $0.93(0.77,1.47) 0.744$ \\
\hline \multicolumn{3}{|c|}{ Parental or guardian respect for privacy } \\
\hline No & Ref & Ref \\
\hline Yes & $1.69(1.16,2.47) 0.007$ & $1.41(0.94,2.11) 0.097$ \\
\hline $\mathrm{N}$ & & 1342 \\
\hline Pseudo $\mathrm{R}^{2}$ & & 0.0734 \\
\hline
\end{tabular}

Source: GSHS, 2012.

AOR-Adjusted Odds Ratio; COR-Crude Odds Ratio; CI-Confidence interval; Ref- Reference.

\section{Discussion}

This study investigated the factors associated withanxiety-induced sleep disturbance among in-school adolescents in Ghana using the 2012 GSHS. The results revealed that the prevalence of anxiety-induced sleep disturbance among in-school adolescents was $13.9 \%$. Hunger, loneliness, suicidal ideation and injury are associated with an anxietyinduced sleep disturbance among in-school adolescents in Ghana. The prevalence of anxiety-induced sleep disturbance in Ghana is similar to what was reported in India [28], Uganda [21], Nigeria [22], and China [29]. Other countries such as Mexico and Bangladesh also reported lower prevalence rates $[1,30]$. Since most of the respondents were in their final year, it is more likely that they were overburdened with high expectations in the final examination from their parents, siblings, and friends. The prevalence rate of anxietyinduced sleep disturbance among the in-school adolescents in Ghana is a public health concern for school directors and the Ministry of Education. Hence, there is a pressing need to develop timely psychological interventions such as field trips [16,31], and effective counseling services in SHS in Ghana to drastically reduce anxiety among adolescents, especially during their exam periods.

Corroborating a previous study [32], adolescents who went hungry were more likely to report anxiety-induced sleep disturbance than those who did not. Since most of the adolescents' abuse and misuse drugs, and their incessant quest for food, would be experienced as a result of the drugs' effect [24]. Additionally, there is a possibility that the adolescents might have used all their money on illicit drugs; hence, they would have nothing to spend on. Very crucially, the implementation of programs that would help intensify the education on the negative impacts of illicit drugs use in SHS in Ghana is laudable.

Lonely adolescents were more likely to report anxiety-induced sleep disturbance than those who did not, a finding that is consistent with several previous studies $[23,24,31,33,34]$. Adolescents who face parental occupational conflicts and come from low-income households with low purchasing power for family needs may experience intermittent loneliness which might trigger social anxiety. Similarly, loneliness could cause anxiety-induced sleep disturbance among adolescents because of inadequate support from friends, loved ones and other influential people who play significant roles in helping them to manage any stressful occurrences or situations they may be facing [1,24]. More importantly, adolescents who experience loneliness are often rejected by their peers. As a result, they find it difficult to share their problems with other people. Such adolescents are quite vulnerable to several anxiety-related health problems [35].

Similar to a previous study [36], adolescents who sustained injury were more likely to report anxiety-induced sleep disturbance than those who did not. An unexpected injury may evoke certain restrictions towards life emergencies and other activities of daily living. Such restrictions on one's daily activities could create irrational thoughts and cause anxiety-induced sleep disturbance $[7,37]$. Also, any unintended injury to regular in-school 
adolescents that may require treatment for several days, weeks, or months in extreme cases might distort their academic pursuits $[17,21]$. In relation to this, any distortion of academic work may scare them, especially as their final examination gets closer. Such adolescents require appropriate self-support interventions that aim at increasing injured persons' ability to independently handle their setbacks (e.g., sustaining an injury).

Other findings revealed that adolescents who experienced suicidal ideations were more likely to report anxiety-induced sleep disturbance compared to those who did not $[17,35,37]$. Most suicidal ideations manifest through persons with history of minor or major psychological, intrapersonal, or individual-level factors and/or social problems (e.g., psychiatric complications, physical illness, and social disconnectedness with loved ones- parents, siblings) [23,37-39]. Such persons usually experience various degree of anxiety disorders such as generalized anxiety disorder, separation anxiety disorder, panic disorder, social phobia, specific phobia, obsessive-compulsive disorder, and posttraumatic or acute stress disorder [12,13]. Therefore, giving enough privacy to adolescents could trigger suicidal ideations or other self-damaging acts $[17,35]$. This finding suggests that enhanced services and education on knowledge of risk and protective strategies for curbing suicidal ideation is needed in the various SHSs in Ghana.

\subsection{Strengths and Limitations}

Unlike any other research, this study has some strengths and limitations. The study relies on a unique data set that links data from standardized data collection through the global health survey. The use of questionnaires for the secondary data permitted the assessment of multiple determinants associated with anxiety-induced sleep disturbance. The relatively large sample size, selected using systematic random procedure with a high response rate warrants generalizability of findings to other homogenous populations, Despite these strengths, there are some limitations that need to be mentioned. First, the assessment of anxiety-induced sleep disturbance was based on self-reports, hence, may be subject to recall and social desirability bias though standardized procedures (e.g., clear and simple instructions) were used to minimize any potential for such biases. Second, the assessment of anxiety-induced sleep disturbance relied on a simple question pertaining to "worry" that may be influenced by several factors such as personality. Due to the cross-sectional design nature of the survey data, the predictors noted in this study are only from a logical perspective devoid of any causality.

\subsection{Practical Implications}

This study provides useful information on the prevalence and predictors of anxietyinduced sleep disturbance among in-school adolescents in Ghana. Recognizing these determinants could help early identification and management of anxiety-induced sleep disturbance in these adolescents. Evidence suggests that anxiety-induced sleep disturbance warrant early detection and management because of the adverse psychological consequences (e.g., impaired cognitive/physical functioning and intra-personal and educational difficulties) among adolescents [40]. To reduce a potential public health burden of the country, the findings necessitate mental health intervention programs (e.g., early school-based screening, cognitive-behavioral therapy, and face-face counseling services) across SHSs in the country. Mental health policy on early detection and reduction of anxiety in SHS would be worthwhile. Future research could target the effectiveness of interventions implemented to help Ghanaian SHS students having anxiety disorders using longitudinal designs.

\section{Conclusions}

Findings of this study indicate that the prevalence of anxiety-induced sleep disturbance among in-school adolescents in Ghana remains high, with hunger, loneliness, injury, and suicidal ideation as associated determinants. Considering the mental health challenges that anxiety-induced sleep disturbance may create for in-school adolescents, understanding the determinants could lead to early detection and management. These findings can 
help with the design of appropriate interventions through effective strategies (e.g., early school-based screening, cognitive-behavioral therapy, and face-face counseling services) to reduce psychosocial problems among in-school adolescents in Ghana.

Supplementary Materials: The following are available online at https:/ / www.mdpi.com/2076-328 X/11/2/20/s1, Table S1: Study variables.

Author Contributions: All listed authors made significant, direct, and academic contributions to the study and agreed to its publication. All authors have read and agreed to the published version of the manuscript.

Funding: The article processing charge (APC) was funded through the Open Access Publication Fund of Bielefeld University.

Institutional Review Board Statement: Not applicable.

Informed Consent Statement: Ethics approval was not required since the data is secondary data and available to the public domain.

Data Availability Statement: The dataset is available for free at: https://www.who.int/ncds / surveillance/gshs/ghanadataset/en/.

Conflicts of Interest: The authors declare no conflict of interest.

\section{References}

1. Khan, M.M.A.; Khan, M.N. Effects of psychosocial and socio-environmental factors on anxiety disorder among adolescents in Bangladesh. Brain Behav. 2020, 10, e01899. [CrossRef]

2. Costello, E.J.; Egger, H.; Angold, A. 10-year research update review: The epidemiology of child and adolescent psychiatric disorders: I. Methods and public health burden. J. Am. Acad. Child Adolesc. Psychiatry 2005, 44, 972-986. [CrossRef]

3. World Health Organization (WHO). Adolescent Mental Health. 2020. Available online: https://www.who.int/news-room/factsheets / detail/adolescent-mental-health (accessed on 28 November 2020).

4. Kessler, R.C.; Angermeyer, M.; Anthony, J.C.; De Graaf, R.O.N.; Demyttenaere, K.; Gasquet, I.; Kawakami, N. Lifetime prevalence and age-of-onset distributions of mental disorders in the World Health Organization's World Mental Health Survey Initiative. World Psychiatry 2007, 6, 168.

5. Ryan, J.L.; Warner, C.M. Treating adolescents with social anxiety disorder in schools. Child Adolesc. Psychiatr. Clin. 2012, 21, 105-118. [CrossRef]

6. Masia Warner, C.; Fisher, P.H.; Shrout, P.E.; Rathor, S.; Klein, R.G. Treating adolescents with social anxiety disorder in school: An attention control trial. J. Child Psychol. Psychiatry 2007, 48, 676-686. [CrossRef] [PubMed]

7. Amu, H.; Seidu, A.A.; Agbemavi, W.; Afriyie, B.O.; Ahinkorah, B.O.; Ameyaw, E.K.; Kissah-Korsah, K. Psychosocial distress among in-school adolescents in Mozambique: A cross-sectional study using the Global School-Based Health Survey data. Child Adolesc. Psychiatry Ment. Health 2020, 14, 1-9. [CrossRef]

8. Beattie, T.S.; Prakash, R.; Mazzuca, A.; Kelly, L.; Javalkar, P.; Raghavendra, T.; Isac, S. Prevalence and correlates of psychological distress among 13-14 year old adolescent girls in North Karnataka, South India: A cross-sectional study. BMC Public Health 2019, 19, 48. [CrossRef]

9. Landazabal, M.G. Psychopathological symptoms, social skills, and personality traits: A study with adolescents. Span. J. Psychol. 2006, 9, 182. [CrossRef]

10. Murphy, W.; de Menil, V.; Betancourt, T.; Collignon, R.; Aikins, A.D.G.; Dawes, A.; Reich, M.R.; Musisi, S.; Kafaar, Z.; Raja, S.; et al The Culture of Mental Illness and Psychiatric Practice in Africa; Indiana University Press: Bloomington, IN, USA, 2015.

11. Sweetland, A.C.; Belkin, G.S.; Verdeli, H. Measuring depression and anxiety in Sub-Saharan Africa. Depress. Anxiety 2014, 31, 223-232. [CrossRef]

12. American Psychiatric Association. Diagnostic and Statistical Manual of Mental Disorders, 4th ed.; DSM-IV; American Psychiatric Association: Washington, DC, USA, 1994.

13. Parekh, R. What are Anxiety Disorders? American Psychiatric Association: Washington, DC, USA, 2019. Available online: https://www.psychiatry.org/patients-families/anxiety-disorders/what-are-anxiety-disorders (accessed on 15 December 2020).

14. Essau, C.A.; Lewinsohn, P.M.; Olaya, B.; Seeley, J.R. Anxiety disorders in adolescents and psychosocial outcomes at age 30. J. Affect. Disord. 2014, 163, 125-132. [CrossRef]

15. Joyce-Beaulieu, D.; Sulkowski, M.L. The diagnostic and statistical manual of mental disorders: (DSM-5) model of impairment. In Assessing Impairment; Springer: Boston, MA, USA, 2016; pp. 167-189.

16. Seidu, A.A. Loneliness among in-school adolescents in Ghana: Evidence from the 2012 Global School-based Student Health Survey. J. Child Adolesc. Ment. Health 2020, 32, 67-76. [CrossRef] 
17. Kahn, J.P.; Cohen, R.F.; Tubiana, A.; Legrand, K.; Wasserman, C.; Carli, V.; Balazs, J.; Banzer, R.; Barilla, F.; Barzilai, S. Influence of coping strategies on the efficacy of YAM (Youth Aware of Mental Health): A universal school-based suicide preventive program. Eur. Child Adolesc. Psychiatry 2020, 29, 1671-1681. [CrossRef]

18. Abdullah, R.I.; Shaker, N.Z. Prevalence of Post-traumatic Stress Disorder and Potentially Traumatic Events among Adolescents in Erbil City. Erbil J. Nurs. Midwifery 2019, 2, 60-69. [CrossRef]

19. Marthoenis, M.; Ilyas, A.; Sofyan, H.; Schouler-Ocak, M. Prevalence, comorbidity and predictors of post-traumatic stress disorder, depression, and anxiety in adolescents following an earthquake. Asian J. Psychiatry 2019, 43, 154-159. [CrossRef]

20. Pengpid, S.; Peltzer, K. Psychological distress and its associated factors among school-going adolescents in Tanzania. Psychol. Stud. 2020, 65, 174-181. [CrossRef]

21. Abbo, C.; Kinyanda, E.; Kizza, R.B.; Levin, J.; Ndyanabangi, S.; Stein, D.J. Prevalence, comorbidity and predictors of anxiety disorders in children and adolescents in rural north-eastern Uganda. Child Adolesc. Psychiatry Ment. Health 2013, 7, 21. [CrossRef]

22. Adewuya, A.O.; Afolabi, M.O.; Ola, B.A.; Ogundele, O.A.; Ajibare, A.O.; Oladipo, B.F. Psychiatric disorders among the HIVpositive population in Nigeria: A control study. J. Psychosom. Res. 2007, 63, 203-206. [CrossRef]

23. Stickley, A.; Koyanagi, A.; Koposov, R.; Blatný, M.; Hrdlička, M.; Schwab-Stone, M.; Ruchkin, V. Loneliness and its association with psychological and somatic health problems among Czech, Russian and US adolescents. BMC Psychiatry 2016, 16, 128. [CrossRef]

24. Acquah, E.O.; Topalli, P.Z.; Wilson, M.L.; Junttila, N.; Niemi, P.M. Adolescent loneliness and social anxiety as predictors of bullying victimisation. Int. J. Adolesc. Youth 2016, 21, 320-331. [CrossRef]

25. Lee, A.; Hankin, B.L. Insecure attachment, dysfunctional attitudes, and low self-esteem predicting prospective symptoms of depression and anxiety during adolescence. J. Clin. Child Adolesc. Psychol. 2009, 38, 219-231. [CrossRef]

26. Swearer, S.; Hymel, S. Bullying and discrimination in schools: Exploring variations across student subgroups. Sch. Psychol. Rev. 2015, 44, 504-509. [CrossRef]

27. World Health Organization. Global School-Based Student Health Survey (GSHS) Purpose and Methodology. 2014. Available online: https://www.who.int/ncds/surveillance/gshs/methodology/en/ (accessed on 11 November 2020).

28. Madasu, S.; Malhotra, S.; Kant, S.; Sagar, R.; Mishra, A.K.; Misra, P.; Ahamed, F. Prevalence and determinants of anxiety disorders among adolescents in a rural community from northern India. Asian Pournal Psychiatry 2019, 43, 137-142. [CrossRef] [PubMed]

29. Qi, H.; Liu, R.; Chen, X.; Yuan, X.F.; Li, Y.Q.; Huang, H.H.; Zheng, Y.; Wang, G. Prevalence of anxiety and associated factors for Chinese adolescents during the COVID-19 outbreak. Psychiatry Clin. Neurosci. 2020. [CrossRef] [PubMed]

30. Caraveo-Anduaga, J.J.; Rodríguez, A.S.; Pérez, J.E. Anxiety syndromes and their correlates in children and adolescents: A two-year-follow-up study at primary health care in Mexico City. In New Insights Anxiety Disorders; Durbano, F., Ed.; INTECH Open Access Publisher: London, UK, 2013; pp. 233-258.

31. Heinrich, L.M.; Gullone, E. The clinical significance of loneliness: A literature review. Clin. Psychol. Rev. 2006, 26, 695-718. [CrossRef]

32. Alexander, K.E.; Siegel, H.I. Perceived hunger mediates the relationship between attachment anxiety and emotional eating. Eat. Behav. 2013, 14, 374-377. [CrossRef]

33. Vijayakumar, L.; Lamech, N. Suicide and Suicidal Behavior in Women. Ment. Health Illn. Women 2020, 35-56. [CrossRef]

34. Muyan, M.; Chang, E.C.; Jilani, Z.; Yu, T.; Lin, J.; Hirsch, J.K. Loneliness and negative affective conditions in adults: Is there any room for hope in predicting anxiety and depressive symptoms? J. Psychol. 2016, 150, 333-341. [CrossRef]

35. Conway, C.C.; Latzman, R.D.; Krueger, R.F. A meta-structural model of common clinical disorder and personality disorder symptoms. J. Personal. Disord. 2020, 34, 88-106. [CrossRef]

36. Schönberger, M.; Ponsford, J.; Gould, K.R.; Johnston, L. The temporal relationship between depression, anxiety, and functional status after traumatic brain injury: A cross-lagged analysis. J. Int. Neuropsychol. Soc. 2011, 17, 781. [CrossRef]

37. Asante, K.O.; Kugbey, N.; Osafo, J.; Quarshie, E.N.B.; Sarfo, J.O. The prevalence and correlates of suicidal behaviours (ideation, plan and attempt) among adolescents in senior high schools in Ghana. SSM-Popul. Health 2017, 3, 427-434. [CrossRef]

38. Hjelmeland, H.; Akotia, C.S.; Owens, V.; Knizek, B.L.; Nordvik, H.; Schroeder, R.; Kinyanda, E. Self-reported suicidal behavior and attitudes toward suicide and suicide prevention among psychology students in Ghana, Uganda, and Norway. Crisis 2008, 29, 20-31. [CrossRef] [PubMed]

39. Osafo, J.; Akotia, C.S.; Andoh-Arthur, J.; Quarshie, E.N.B. Attempted suicide in Ghana: Motivation, stigma, and coping. Death Stud. 2015, 39, 274-280. [CrossRef] [PubMed]

40. Bhatia, M.S.; Goyal, A. Anxiety disorders in children and adolescents: Need for early detection. J. Postgrad. Med. 2018, 64, 75-76. [CrossRef] [PubMed] 